\title{
Avaliação do desempenho de compósito alternativo destinado aos sistemas urbanos e moradias de baixo custo
}

\author{
Performance evaluation of an alternative composite for \\ urban systems and low-cost housing
}

\section{Paulo Gedeão Barroso Gomes Júnior \\ Sergio Rafael Cortes de Oliveira José Luiz Ernandes Dias Filho}

\section{Resumo}

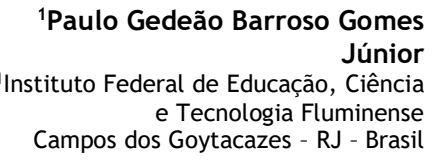

${ }^{2}$ Sergio Rafael Cortes de Oliveira ${ }^{2}$ Instituto Federal de Educação, Ciência e Tecnologia Fluminense Campos dos Goytacazes - RJ - Brasil

\footnotetext{
${ }^{3} J o s e ́$ Luiz Ernandes Dias Filho ${ }^{3}$ Universidade Estadual do Norte Fluminense Darcy Ribeiro Campos dos Goytacazes - RJ - Brasil
}

Recebido em 30/05/20 Aceito em 03/12/20

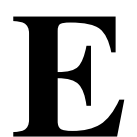

ste artigo traz um estudo sobre um compósito de cimento, resíduo industrial de lodo de papel eflakes de PET, visando sua potencialização para possível destinação em sistemas urbanos e moradias de baixo custo. Justifica-se pelos problemas socioambientais relacionados aos consumos de matérias-primas naturais e pela deposição indevida de produtos e resíduos no ambiente. Para isso, foram testadas as proporções 1:3, 1:4 e 1:5 de cimento e resíduos, com substituições do volume de lodo de papel por PET nas taxas de $10 \%, 20 \%$ e 30\%. Foram avaliadas propriedades físico-mecânicas - como resistência à compressão, absorção de água e porosidade aos 28 e 90 dias em amostras não degradadas - e parâmetros de desgaste ao atrito. As propriedades físico-mecânicas foram aferidas também aos 35 e 42 dias em amostras que passaram por ciclos de degradação acelerada. De forma geral, notou-se aumento da resistência mecânica com a cura e diminuição com a inserção de lodo. O material apresentou baixa degradação nos ensaios de desgaste. Quanto à absorção de água e à porosidade, os valores aumentaram conforme o acréscimo de resíduo e com a cura, facilmente contornável com a redução de lodo e adoção de soluções impermeabilizantes.

Palavras-chave: Sustentabilidade. Resíduos sólidos. Material de construção. Durabilidade.

\begin{abstract}
This paper presents a cement composite, industrial sludge waste and PET flakes composite, aiming at its potentialization for possible use in urban systems and low-cost housing. It is justified by the socio-environmental problems related to the consumption of natural raw materials and by the inappropriate disposal of products and waste in the environment. Hence, the proportions 1:3, 1:4 and 1:5 of cement and residues were tested, with sludge volume substitutions by PET at the rates of 10\%, 20\% and 30\%. Physicalmechanical properties such as compressive strength, water absorption and porosity at 28 and 90 days were evaluated in non-degraded samples, in addition to friction wear parameters. The physical-mechanical properties were also measured at 35 and 42 days in samples that underwent accelerated degradation cycles. In general, there was an increase in mechanical strength with curing and a decrease with the insertion of sludge. The material showed low degradation in the wear tests. As for water absorption and porosity, the values increased with the addition of residue and with curing, easily bypassed with the reduction of sludge and the adoption of waterproofing solutions.
\end{abstract}

Keywords: Sustainability. Solid waste. Construction material. Durability. 


\section{Introdução}

A Conferência das Nações Unidas sobre Desenvolvimento Sustentável Rio+20, com o apoio das lideranças políticas mundiais envolvidas, lançou uma cartilha (ORGANIZAÇÃO..., 2019) com a intenção de angariar esforços que buscassem fortalecer a paz mundial e a erradicação da pobreza. A cartilha está dividida em dezessete declarações conhecidas como "Objetivos do Desenvolvimento Sustentável (ODS)", que, detalhadas em metas e ações, visam colocar em prática medidas enfáticas e transformadoras para a construção de um caminho que contribua para um mundo resiliente e pautado nas dimensões econômica, social e ambiental do desenvolvimento sustentável.

Entre os ODS (ORGANIZAÇÃO..., 2019), o objetivo número 11 trata da transformação das cidades e dos assentamentos humanos em espaços inclusivos, seguros e sustentáveis; no que se refere aos resíduos sólidos, tem como meta reduzir o impacto ambiental negativo per capita das cidades, inclusive prestando especial atenção na qualidade do ar e na gestão de resíduos sólidos urbanos, como resíduos de construção e demolição, matéria orgânica, metais, plásticos, vidro, papel e papelão, por exemplo, além de outros resíduos no estado sólido e semissólido até 2030. O objetivo número 12 busca assegurar padrões de produção e consumo sustentáveis tendo como uma das metas alcançar o manejo ambientalmente saudável dos produtos químicos e de todos os resíduos, ao longo de todo seu ciclo de vida, de acordo com os marcos internacionais acordados. Este objetivo visou também reduzir significativamente a liberação dos produtos químicos e resíduos para o ar, a água e o solo, minimizando seus impactos negativos sobre a saúde humana e o meio ambiente até 2020, assim como minimizar substancialmente a geração de resíduos por meio da prevenção, da redução, da reciclagem e do reúso até 2030 e incentivar as empresas - especialmente as grandes e transnacionais - a adotarem práticas sustentáveis e a integrar informações de sustentabilidade em seu ciclo de relatórios.

Sobre a questão da minimização dos impactos ambientais, um produto consumido em larga escala e significado de progresso e industrialização, o cimento Portland, representa um grande desafio às demandas mundiais de redução da emissão do dióxido de carbono $\left(\mathrm{CO}_{2}\right)$ (OLIVETTI; CULLEN, 2018). A indústria cimenteira do Brasil teve início na década de 1920 do século passado; a produção nacional começou a superar a exportação a partir de 1930 e atingiu seu ápice nas obras de infraestrutura em 1970. Dados de 2016 do Sindicato Nacional da Indústria do Cimento mostraram que o Brasil dispõe de um parque industrial composto por 100 fábricas que são controladas por 24 grupos industriais e que estão espalhadas em 24 estados da federação, contando com uma produção estimada de $5,70 \times 10^{7}$ toneladas do produto (SINDICATO..., 2016).

Embora as indústrias adotem medidas que minimizam os impactos da fabricação do cimento, a geração do $\mathrm{CO}_{2}$ é intrínseca à produção do insumo. Rocha (2016) indicou que a produção de cimento Portland é responsável por cerca de 5\% das emissões globais de $\mathrm{CO}_{2}$ e de 3,8\% do consumo de energia global. Por sua vez, Oliveira (2007) e Santoro e Kripka (2016) relataram que a questão das emissões associadas à produção do clínquer é um dos principais componentes da pegada carbônica da construção (OLIVETTI; CULLEN, 2018), indicando que cerca de $6 \%$ do $\mathrm{CO}_{2}$ gerado no Brasil seja oriundo da descarbonatação do calcário que ocorre durante a produção de cimento.

Outra matéria-prima que representa um dos maiores problemas no mundo todo é o plástico. Seu alto consumo e, consequentemente, seu descarte vêm provocando desequilíbrios ambientais e impactos que perduram por longo prazo, gerando produção elevada de lixo que, inclusive, chega até os mares. Isto traz à tona a discussão sobre a valorização dos resíduos, enfatizando a necessidade de protocolos de gestão de resíduos mais sustentáveis e rentáveis (ABDEL-SHAFY; MANSOUR, 2018).

Em uma reportagem, a Revista Pesquisa FAPESP apresentou o panorama dos problemas ocasionados pelo descarte irregular do plástico pelo mundo: no Brasil, em 2016, foram contabilizadas cerca de 11,3 toneladas de lixo plástico, colocando o país como o quarto maior produtor de lixo plástico no mundo. Desse montante, $91 \%$ foi coletado por serviços de limpeza urbana, enquanto apenas 1,28\% foi destinado à reciclagem. Os números foram levantados a partir de um banco de dados entre a World Wide Fund for Nature, organização não-governamental que atua em favor do meio ambiente, e o Banco Mundial. Embora contestados pelas lideranças da indústria plástica no país, que alegam distorção dos números, há um consenso entre os agentes envolvidos sobre a falta de estímulo e de políticas públicas quanto à reciclagem do plástico e o baixo incentivo à economia circular, além da necessidade de realizar ajustes importantes na cadeia logística e no processo de fabricação de determinados tipos de polímeros que inviabilizam sua reciclagem (VASCONCELOS, 2019). 
No caso do politereftalato de etileno (PET), por exemplo, em 2015 foram consumidas cerca de 537 mil toneladas de resina de PET para fabricação de embalagens; com o aumento da conscientização ambiental, a aplicação do processo de reciclagem de embalagens de PET tem aumentado, mesmo que longe do ideal (SANTOS et al., 2018). As indústrias têxteis, de embalagens de alimentos e cosméticos, cordas, faixas e correias são as maiores consumidoras de PET reciclado (SANTOS et al., 2018).

Mercante et al. (2018) ressaltaram o fato de o PET ser o tipo de plástico mais estudado em termos de práticas sustentáveis, mas que faltam trabalhos em países em desenvolvimento como os da América Latina. A reciclagem de resíduos plásticos proporciona um acréscimo na vida útil do material, que, somada às boas práticas ambientais, pode gerar valor agregado aos segmentos econômicos envolvidos. Um ponto vantajoso para o PET é sua capacidade de ser um material totalmente reciclável; na construção civil, seu uso ocorre pelas substituições em agregados de concreto e argamassas, e como isolante térmico, por exemplo (NOVÁKOVÁ et al., 2017), além de ser utilizado na fabricação de torneiras, tubos e conexões, telhas, piscinas, bancadas, tintas e caixas d'água (ROCHA, 2017).

Diversas são as contribuições da ciência para o desenvolvimento de novas alternativas para os materiais tradicionalmente utilizados pela construção civil, seja na redução do cimento e de agregados pela substituição por diversos elementos descartados em processos industriais, ou na reinvenção de determinados produtos, como tijolos, blocos estruturais, blocos intertravados para pavimentação, entre outros. Algumas dessas contribuições são descritas adiante.

Azevedo et al. (2018) empregaram resíduos de efluente de uma indústria de papel na fabricação de argamassas a fim de garantir a viabilidade econômica deste subproduto no ciclo da construção civil. Para a realização de ensaios de resistência mecânica e desgaste, foram confeccionadas amostras prismáticas medindo $4 \times 4 \times 16 \mathrm{~cm}$ no traço de 1:1:6 de cimento/resíduo/areia, com incorporação em massa de resíduo de $0 \%, 5 \%, 10 \%, 15 \%$ e $20 \%$ e relações de água e aglomerante de 0,80 a 0,95 . Nos ensaios de resistência à compressão, aos 28 dias, as amostras atingiram resistências de 2,29 $\mathrm{MPa}(20 \%$ de resíduo) a 3,10 $\mathrm{MPa}(0 \%$ de resíduo); com relação à perda de massa nos ciclos de saturação e secagem, seu valor variou de $7,70 \%(0 \%$ de lodo de papel) a $16,67 \%$ (20\% de lodo de papel). Os autores sugeriram que, para a utilização como argamassas e revestimentos, o nível tolerável de incorporação em massa de resíduos deve ser de 10\%. A inserção deste tipo de resíduo dentro de uma cadeia produtiva está de acordo com as demandas mundiais de sustentabilidade, como preservação dos recursos hídricos e do solo e ocupação de aterros sanitários, por exemplo.

Amaral Júnior et al. (2017) estudaram a influência da aplicação de fibras poliméricas nas propriedades mecânicas do concreto. Confeccionaram amostras cilíndricas de $10 \mathrm{~cm}$ de diâmetro por $20 \mathrm{~cm}$ de altura no traço 1:2:2 com relação água/cimento de 0,61 , resistência característica do concreto de $25 \mathrm{MPa}$ e adição de fibras poliméricas na proporção de $1 \%$ em volume da matriz do compósito. Foram empregadas fibras poliméricas de polipropileno (PP) e de polietileno de alto módulo (em inglês, high modulus polyethylene [HMPE]) - esta última fibra utilizada em cabos submarinos para serviços de ancoragem. Os ensaios de resistência à compressão mostraram que a adição de PP e de HMPE representaram um ganho de resistência na ordem de $3,6 \%$ e 7,2\%, respectivamente, comparados aos resultados sem adição de fibras. O acréscimo de resistência se repete tanto para a resistência à tração quanto para a tenacidade do concreto.

Vieira et al. (2016) enfatizaram o pioneirismo europeu no emprego dos resíduos de efluentes das indústrias de papel na confecção de materiais compósitos. Sua aplicação, também pioneira em escala industrial, substituiu a argila utilizada para a fabricação de tijolos convencionais por teores de lodo de papel, a uma proporção de $10 \%$ da massa da argila. Foram realizados ensaios de retração linear, absorção de água e resistência mecânica para as amostras submetidas à queima a $750{ }^{\circ} \mathrm{C}$, seguindo os procedimentos da indústria cerâmica. Além disso, o estudo avaliou o impacto ambiental provocado pela emissão dos gases do processo de queima em conformidade com as normas brasileiras. Os resultados apontaram que a retração linear do tijolo variou de $0,83 \pm 0,02 \%$, sem incorporação de resíduo, a $0,81 \pm 0,03 \%$, com $10 \%$ de lodo de papel, que a absorção de água variou de $21,1 \pm 0,4 \%$ a $22,8 \pm 0,7 \%$ e que a resistência à compressão uniaxial

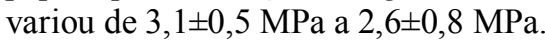

Uma técnica construtiva que atende aos requisitos socioambientais é a fabricação de tijolos de solo-cimento. Entre suas vantagens, destacam-se o baixo custo de confecção, a não queima do material, a economia dos gastos de energia atrelados e a sua contribuição como material de construção especialmente em países em desenvolvimento (SIQUEIRA et al., 2016), embora já seja utilizado em países desenvolvidos. Em 1935, nos Estados Unidos, o solo-cimento era empregado experimentalmente em pavimentos rodoviários, com resultados satisfatórios e contribuindo para o aumento das pesquisas na área, a evolução de sua técnica de 
uso e controle de qualidade (CORDEIRO et al., 2006).

Castro et al. (2016), por exemplo, incorporaram coprodutos siderúrgicos como massa do pó de balão coletado em alto-forno, despoeiramento de aciaria elétrica e escória granulada de forno elétrico a arco em compósitos de solo-cimento. Foram confeccionados corpos de prova (CPs) no formato de blocos no traço de 1:6 de cimento e solo, com uma substituição em massa do solo em taxas de $20 \%, 10 \%$ e $20 \%$ dos resíduos citados, alguns ainda com adição de pós obtidos da produção de blocos de solo-cimento, e avaliadas as propriedades físico-mecânicas como absorção de água e resistência à compressão. A formulação com $20 \%$ de escória de forno elétrico a arco e $10 \%$ de reaproveitamento de pó de solo-cimento foi a única que atendeu concomitantemente aos valores normativos de absorção de água e resistência à compressão para blocos de solo-cimento, alcançando $16 \%$ e 2,0 MPa, respectivamente. Os resultados indicam a potencialidade da aplicação desses coprodutos para a confecção de uma alvenaria alternativa.

Nesse contexto, o objetivo do presente artigo é apresentar um compósito constituído de cimento, resíduos de efluente de uma indústria de papel e flakes de PET, potencializando-o como material de construção possivelmente aplicável no sistema urbano - por exemplo, em mobiliários urbanos, pavimentos para ciclovias e calçadas e, ainda, em moradias de baixo custo - e avaliando suas propriedades físico-mecânicas (resistência à compressão, absorção de água e porosidade) na condição intacta e na condição degradada após ciclos de saturação e secagem, além da resistência ao desgaste por atrito.

Após estudos prévios a partir dos trabalhos de Azevedo et al. (2018), Amaral Júnior et al. (2017), Cerqueira (2017), Castro et al. (2016), Siqueira et al. (2016), Vieira et al. (2016), Pinheiro (2008), Paiva (2007) e Cordeiro et al. (2006), determinou-se que os traços adotados para a fabricação dos CPs seriam de 1:3, 1:4 e 1:5 em proporção de cimento e resíduos (lodo de papel e PET), calculados em relação ao volume dos CPs. A inserção dos flakes de PET sobre o volume de lodo de papel empregado ocorreu em taxas de substituição de $10 \%, 20 \%$ e $30 \%$ nos três traços adotados.

O emprego do lodo de papel e a substituição de parte dele por flakes de PET estão em consonância com os ODS que regem sobre a produção e o manejo dos resíduos sólidos (ORGANIZAÇÃO..., 2019), assim como a Política Nacional de Resíduos Sólidos, que tem como um dos seus objetivos a criação de mecanismos que possibilitem a redução e a extinção do manejo irregular dos resíduos sólidos urbanos e dos demais produtos descartados das cadeias produtivas da economia brasileira, responsabilizando todos os agentes envolvidos na gestão compartilhada dos resíduos (BRASIL, 2010).

Assim, apoiando-se em Olivetti e Cullen (2018), este trabalho tem como justificativa a crescente demanda das cadeias produtivas por insumos naturais e, consequentemente, o descarte inadequado desses subprodutos, acarretando graves problemas socioambientais. O crescimento populacional, a expansão territorial urbana e a ampliação do sistema de produção e de consumo industrial têm contribuído para agravar essas condições ambientais (MARCHI, 2015).

Segundo Foster et al. (2016), tendo em vista que as destinações atuais não são capazes de solucionar satisfatoriamente os problemas ambientais relacionados aos resíduos sólidos, existe a necessidade de encontrar não apenas alternativas de disposição final mas opções que considerem o problema dos resíduos de forma sistêmica e que englobem o modelo produtivo como um todo. Há de ser considerada a responsabilidade compartilhada, que tem como personagens envolvidos o governo, a indústria, o comércio e o consumidor, cujos objetivos são a redução da geração de resíduos sólidos, do desperdício de materiais, da poluição e dos danos ambientais (RODRIGUES; MENTI, 2016), abrangendo o fomento de investimentos por parte dos fabricantes, dos importadores, dos distribuidores e dos comerciantes no desenvolvimento, na fabricação e na colocação no mercado de produtos aptos para a reutilização, a reciclagem e a logística reversa (RODRIGUES; MENTI, 2016; SOLER, 2015).

\section{Materiais e métodos}

Os CPs cilíndricos foram confeccionados com proporções em volume de 1:3, 1:4 e 1:5 de cimento e lodo de papel, substituindo-se este último por flakes de PET, em taxas de $10 \%, 20 \%$ e $30 \%$ do volume nos três traços adotados. Foram avaliadas propriedades físico-mecânicas como resistência à compressão, absorção de água e porosidade das amostras intactas submetidas à cura úmida para as idades de 28 e 90 dias, além da resistência ao desgaste por atrito pelo ensaio slake durability para as mesmas idades. As três primeiras propriedades foram avaliadas também para amostras submetidas a ciclos de degradação acelerada por saturação e secagem. Após a cura úmida até a idade de 28 dias, parte do número de CPs foi inserida no equipamento de saturação e secagem e ficou sob a ação dos ciclos acelerados durante 7 dias (equivalente à 
idade de 35 dias no tempo total) e durante 14 dias (equivalente à idade de 42 dias, considerando o tempo total). Foram necessários $384 \mathrm{CPs}$ para realizar os ensaios previstos.

A Tabela 1 apresenta os 12 traços confeccionados, com as discriminações em massa (primeira linha) e em volume (segunda linha) para cada percentual de teor de PET.

\section{Materiais utilizados}

O compósito proposto, por ausência de normas específicas, tem analogia com os constituintes do solocimento. No entanto, o emprego do solo foi substituído pelo resíduo de efluentes da estação de tratamento de uma indústria de papel; além disso, frações desse resíduo foram substituídas por flakes de PET. Para confeccionar os $384 \mathrm{CPs}$, foram consumidos aproximadamente 44,50 kg de cimento Portland tipo CP-II-E, $97,40 \mathrm{~kg}$ de resíduo sólido da estação de tratamento de efluentes de indústria de papel, 12,40 kg de flakes de PET e 121,20 litros de água.

\section{Cimento Portland tipo CP-II-E}

Para confeccionar as amostras, foi utilizado o cimento Portland tipo CP-II-E, por ser de fácil aquisição e pela sua versatilidade nas aplicações correntes, seja sob a forma de argamassa, concreto armado, elementos prémoldados e artefatos de cimento. Além disso, esse produto tem alta resistência ao ataque de sulfatos com moderado calor de hidratação, processo importante na cura do concreto e, consequentemente, ganho de resistência e durabilidade do composto (NEVILLE; BROOKS, 2013).

\section{Resíduo sólido da estação de tratamento de efluentes de indústria de papel}

O resíduo sólido empregado é proveniente da fabricação de papéis por parte de uma companhia industrial localizada próxima ao município de Campos dos Goytacazes, no interior do estado do Rio de Janeiro, do mesmo tipo utilizado por Azevedo et al. (2018) e Vieira et al. (2016). O lodo de papel, como é chamado, é gerado como efluente primário da estação de tratamento das águas residuais do processo de fabricação do papel. Esse resíduo é disponibilizado pela companhia em forma pelotizada e bastante úmido, sendo necessário realizar processos de secagem (exposição ao sol), moagem (realizado num moinho de bolas), refino (até que o material passe totalmente na peneira de abertura $0,50 \mathrm{~mm}$ ) e peneiramento para se obter uma composição fina e homogênea (VIEIRA et al., 2016). Considerando a análise granulométrica do resíduo empregado na composição dos CPs, 51,30\% é equivalente à porcentagem de fração silte e 33,50\% é equivalente à fração argila, o que o caracteriza como um material silte-argiloso. $O$ teor de umidade superficial encontrado foi de 46,42\%. A massa específica do material é de aproximadamente $1,95 \mathrm{~g} / \mathrm{cm}^{3}$.

Ensaios de caracterização química do resíduo por espectrometria de fluorescência de raios-X indicam que o lodo de papel é composto de óxido de cálcio $(\mathrm{CaO})$ ligado à calcita e presente nas aparas utilizadas para a fabricação do papel, sílica $\left(\mathrm{SiO}_{2}\right)$ e alumina $\left(\mathrm{Al}_{2} \mathrm{O}_{3}\right)$ ligadas à estrutura da caulinita e carbono orgânico $(\mathrm{C})$ devido à celulose, conforme observado também por Pinheiro (2008). Além disso, apresenta uma coloração cinza e, quanto à periculosidade, de acordo com a classificação de resíduos sólidos da NBR 10004 (ABNT, 2004a), é do tipo Classe II-A, isto é, não perigoso e não inerte.

Tabela 1 - Traços em massa (primeira linha) e em volume (segunda linha) dos compósitos

\begin{tabular}{c|c|c|c}
\hline \multirow{2}{*}{ Teores de PET (\%) } & \multicolumn{3}{|c}{ Traços } \\
\cline { 2 - 4 } & $\mathbf{1 : 3}$ & $\mathbf{1 : 4}$ & $\mathbf{1 : 5}$ \\
\hline \multirow{2}{*}{$0 \%$} & $1: 2,04: 0$ & $1: 2,72: 0$ & $1: 3,40: 0$ \\
& $1: 3,00: 0$ & $1: 4,00: 0$ & $1: 5,00: 0$ \\
\hline \multirow{2}{*}{$10 \%$} & $1: 1,83: 0,14$ & $1: 2,45: 0,19$ & $1: 3,06: 0,24$ \\
& $1: 2,70: 0,30$ & $1: 3,60: 0,40$ & $1: 4,50: 0,50$ \\
\hline \multirow{2}{*}{$20 \%$} & $1: 1,63: 0,29$ & $1: 2,17: 0,38$ & $1: 2,72: 0,48$ \\
& $1: 2,40: 0,60$ & $1: 3,20: 0,80$ & $1: 4,00: 1,00$ \\
\hline \multirow{2}{*}{$30 \%$} & $1: 1,43: 0,43$ & $1: 1,90: 0,58$ & $1: 2,38: 0,72$ \\
& $1: 2,10: 0,90$ & $1: 2,80: 1,20$ & $1: 3,50: 1,50$ \\
\hline
\end{tabular}




\section{Flakes de PET}

O polímero utilizado para a elaboração dos CPs foi adquirido na empresa Masterflake, da cidade de GuaíbaRS, uma vez que na região de desenvolvimento da pesquisa não foram encontrados fornecedores que oferecessem o produto fragmentado para a devida incorporação no compósito. O material foi empregado na condição de flake (ou floco), de formato pontiagudo, resultante da moagem de garrafas PET. A análise granulométrica realizada caracteriza o material como equivalente em $62 \%$ a uma areia grossa, em $34 \%$ a uma areia média e em $4 \%$ a uma areia fina. Além disso, o diâmetro efetivo $\mathrm{D}_{10}$ foi igual a $0,3 \mathrm{~mm}$, o diâmetro $\mathrm{D}_{30}$ foi de $0,52 \mathrm{~mm}$ e o diâmetro $\mathrm{D}_{60}$ foi de $0,95 \mathrm{~mm}$, com um coeficiente de uniformidade de 3,17 e coeficiente de curvatura de 0,95 . A massa específica do material foi de aproximadamente $1,38 \mathrm{~g} / \mathrm{cm}^{3}$.

\section{Água}

Utilizou-se a água fornecida pela companhia de abastecimento do município de Campos dos Goytacazes-RJ.

Inicialmente, foi determinada uma relação água/cimento igual a 2,0, uma vez que o resíduo utilizado nesta pesquisa apresenta alta capacidade de absorção de água (PAIVA, 2007; PINHEIRO, 2008). No entanto, à medida em que a quantidade de resíduo foi aumentando, a mistura não obteve a fluidez necessária para preencher os CPs, necessitando de acréscimo de água. Nos traços 1:4 e 1:5 se utilizou até $12 \%$ a mais da água necessária para o traço 1:3.

\section{Formato, quantidade e processo de confecção dos CPs}

Para realizar a pesquisa, foram confeccionados CPs cilíndricos de $5 \mathrm{~cm}$ de diâmetro e $10 \mathrm{~cm}$ de altura obedecendo às proporções normativas. A necessidade de reduzir o tamanho das amostras (em vez de $15 \mathrm{~cm}$ $\times 30 \mathrm{~cm}$ ) se deu por conta da diminuição do consumo de materiais necessários para a fabricação do compósito.

Para produzir os CPs, após os processos de aquisição e preparo dos materiais, os corpos de prova foram separados e ensacados de acordo com a quantidade necessária para cada traço. Os materiais foram colocados em uma batedeira industrial planetária obedecendo à sequência cimento, resíduo de lodo de papel, flakes de PET e, por fim, água, garantindo maior homogeneização da mistura que, após esse procedimento, era imediatamente levada até a moldagem. Para a moldagem dos CPs, aplicou-se desmoldante em cilindros de PVC. A mistura foi colocada nos moldes que ficaram sobre uma superfície plana e, 24 horas depois, os CPs foram desmoldados e colocados em recipientes com uma mistura de água e cal.

Para o traço 1:3 foi possível obter uma composição satisfatória, e o produto final foi inserido nos moldes de PVC devidamente preparados com desmoldante. Com a utilização de uma proveta, foi medida a quantidade de água inserida no recipiente, constatando-se o acréscimo de $12 \%$ para os traços 1:4 e 1:5 em relação ao traço 1:3. À medida em que a água foi adicionada na composição, sua absorção pelo lodo de papel foi elevada, sendo necessária maior quantidade.

\section{Ensaios realizados}

Após o processo de cura úmida de 28 dias, foram realizados ensaios de resistência à compressão uniaxial, de absorção de água e de porosidade. O processo foi repetido para as amostras que continuaram sob cura úmida até a idade de 90 dias. Uma parte da amostragem foi retirada da cura úmida aos 28 dias e inserida no equipamento de degradação acelerada por saturação e secagem por mais 7 e 14 dias (equivalente a 35 e 42 dias no tempo total). Essas amostras degradadas de forma acelerada também foram ensaiadas quanto à resistência à compressão, à absorção de água e à porosidade. Foram realizados, ainda, ensaios de desgaste por atrito no slake durability nas idades de 28 e 90 dias.

Embora a essência do compósito tenha como referência o composto de solo-cimento, na ausência de normativas específicas, além das normas de solo-cimento, outras foram utilizadas, especialmente aquelas ligadas à produção de blocos de alvenarias e possíveis aplicações do material proposto no artigo. De maneira geral, a fim de balizar os procedimentos de ensaios bem como encontrar valores comparativos para os parâmetros avaliados, foi utilizado o conjunto de normas brasileiras NBR 15270-1 (ABNT, 2005a), NBR 15270-2 (ABNT, 2005b) e NBR 15270-3 (ABNT, 2005c), referentes a blocos cerâmicos para vedação e alvenaria estrutural; NBR 12766 (ABNT, 1992), de rochas aplicadas em revestimentos; NBR 10836 (ABNT, 2004b), referente a blocos de solo-cimento sem função estrutural; e a norma americana D4644 (AMERICAN..., 2008). 
A Figura 1 apresenta a esquematização dos materiais utilizados, dos traços adotados, do processo de cura e dos ensaios realizados para avaliação das propriedades.

Para realizar os ensaios da pesquisa, foram confeccionados 384 CPs. A Tabela 2 apresenta as quantidades de CPs por cada traço utilizados em cada ensaio e em cada idade de sua realização. Para o ensaio de resistência à compressão foram confeccionados 3 ou 5 CPs. O número inferior de CPs para as amostras que foram submetidas aos ciclos de saturação e secagem (idades de 35 e 42 dias) - 3 em vez de 5 - se deu por causa da capacidade da câmara de degradação. Para medir a absorção de água/porosidade foram confeccionados 3 CPs. Por sua vez, para realizar o ensaio de desgaste pelo slake durability, foram confeccionados 2 CPs, que foram divididos em 10 pequenas amostras, com massas individuais que variaram de 40 a 60 gramas e massa total entre 450 e 550 gramas. Não foram realizados ensaios de desgaste pelo slake durability nas idades de 35 e 42 dias.

\section{Resistência à compressão uniaxial}

O ensaio de resistência à compressão uniaxial foi realizado de acordo com a NBR 7215 (ABNT, 1996). Para tal, os CPs foram retirados da cura nas idades de 28 e 90 dias para a realização do ensaio com as amostras intactas. Foram ensaiadas, também, amostras retiradas da cura aos 28 dias e submetidas aos ciclos de degradação acelerada por saturação e secagem durante 7 ou 14 dias, com idades de 35 e 42 dias, respectivamente.

Figura 1 - Esquema da metodologia com as etapas de confecção dos CPs, o processo de cura e os ensaios realizados

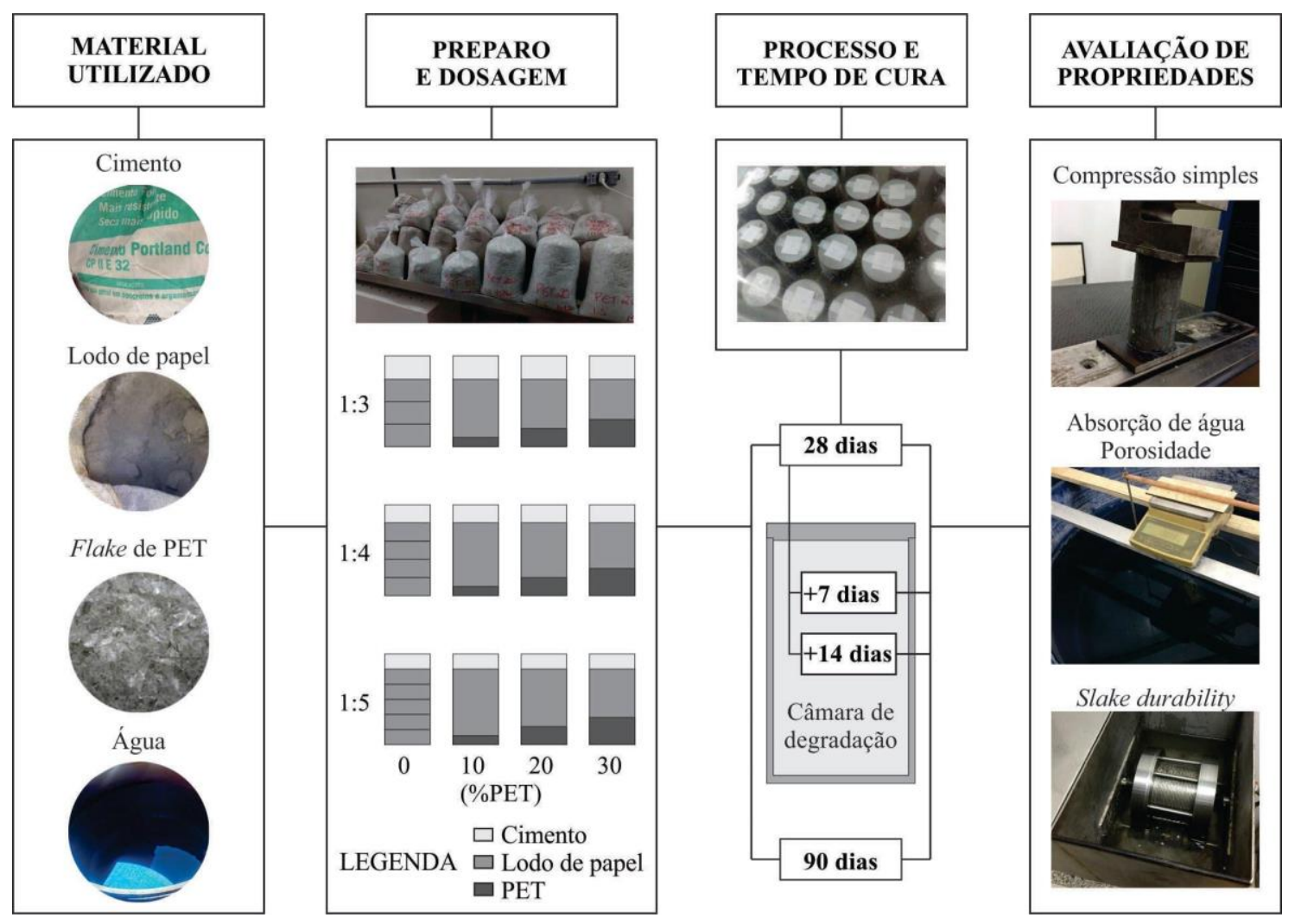

Tabela 2 - Quantidade de CPs utilizados por cada traço em cada idade de ensaio

\begin{tabular}{l|c|c|c|c}
\hline \multirow{2}{*}{\multicolumn{1}{c|}{ Ensaios }} & \multicolumn{4}{c}{ Idades } \\
\cline { 2 - 5 } & $\mathbf{2 8}$ dias & $\mathbf{3 5}$ dias & $\mathbf{4 2}$ dias & $\mathbf{9 0}$ dias \\
\hline Resistência à compressão & 5 & 3 & 3 & 5 \\
Absorção de água/porosidade & 3 & 3 & 3 & 3 \\
Slake durability & 2 & - & - & 2 \\
\hline
\end{tabular}


O ensaio foi realizado na prensa modelo EMIC DL30 e seguiu a uma velocidade de aplicação de carga de $(50 \pm 10) \mathrm{N} / \mathrm{s}$ até a ruptura dos CPs. A tensão de resistência à compressão uniaxial $\sigma(\mathrm{MPa})$ foi determinada pela Equação 1, sendo $F$ a força uniaxial máxima compressiva $(\mathrm{N})$ e $A$ a área da seção do corpo de prova $(\mathrm{mm})$.

$$
\sigma=\frac{F}{A}
$$

Para fins comparativos, admitiram-se os valores de referência de resistência à compressão uniaxial de 1,5 MPa e de 3,0 MPa, estabelecidos na NBR 15270-1 (ABNT, 2005a) para blocos cerâmicos com furo horizontal e com furo vertical, respectivamente, aplicados como alvenaria de vedação, assim como a média dos valores de resistência à compressão aos 28 dias maior ou igual a 2,0 $\mathrm{MPa}$ para blocos de solo-cimento sem função estrutural, estabelecida pela NBR 10836 (ABNT, 2004b).

\section{Resistência ao desgaste pelo slake durability}

O ensaio de desgaste por atrito slake durability é muito utilizado para medir a capacidade abrasiva de rochas brandas, além de ser uma forma de avaliar a durabilidade do material investigado, mas tem sido utilizado na caracterização de outros tipos de rochas e materiais (AHMAD et al., 2017; MOMENI et al., 2017; CERYAN, 2015). O índice obtido pelo ensaio pode ser utilizado de diferentes formas, sendo correlacionado às características químicas, mecânicas e às condições de intemperismo da rocha analisada (CERYAN, 2015).

O ensaio seguiu uma orientação adaptada da norma americana D4644-08 (AMERICAN..., 2008) e foi realizado no equipamento de desgaste da Universidade Estadual do Norte Fluminense Darcy Ribeiro (UENF), conforme ilustra a Figura 2.

Para realizar os ensaios, os CPs foram retirados da cura nas idades de 28 e 90 dias. Para cada traço, os CPs confeccionados foram divididos em 10 amostras, com massas individuais que variaram de 40 a 60 gramas e um total entre 450 a 550 gramas. As amostras foram colocadas na estufa, a uma temperatura de $105{ }^{\circ} \mathrm{C}$ durante 24 horas, medindo a massa seca do conjunto; posteriormente, foram inseridas em um recipiente cilíndrico revestido por malha metálica com abertura de $2 \mathrm{~mm}$ colocado dentro de um tanque metálico parcialmente preenchido com água. $\mathrm{O}$ ciclo de desgaste consistiu em submeter o conjunto amostral a uma velocidade de $20 \mathrm{rpm}$ durante dez minutos. A perda de massa foi verificada medindo a nova massa da amostra depois do ciclo de desgaste após secagem em estufa. O procedimento foi repetido cinco vezes para cada traço adotado.

Figura 2 - Equipamento de desgaste da UENF: (a) foto geral; (b) motor elétrico e (c) câmara de degaste
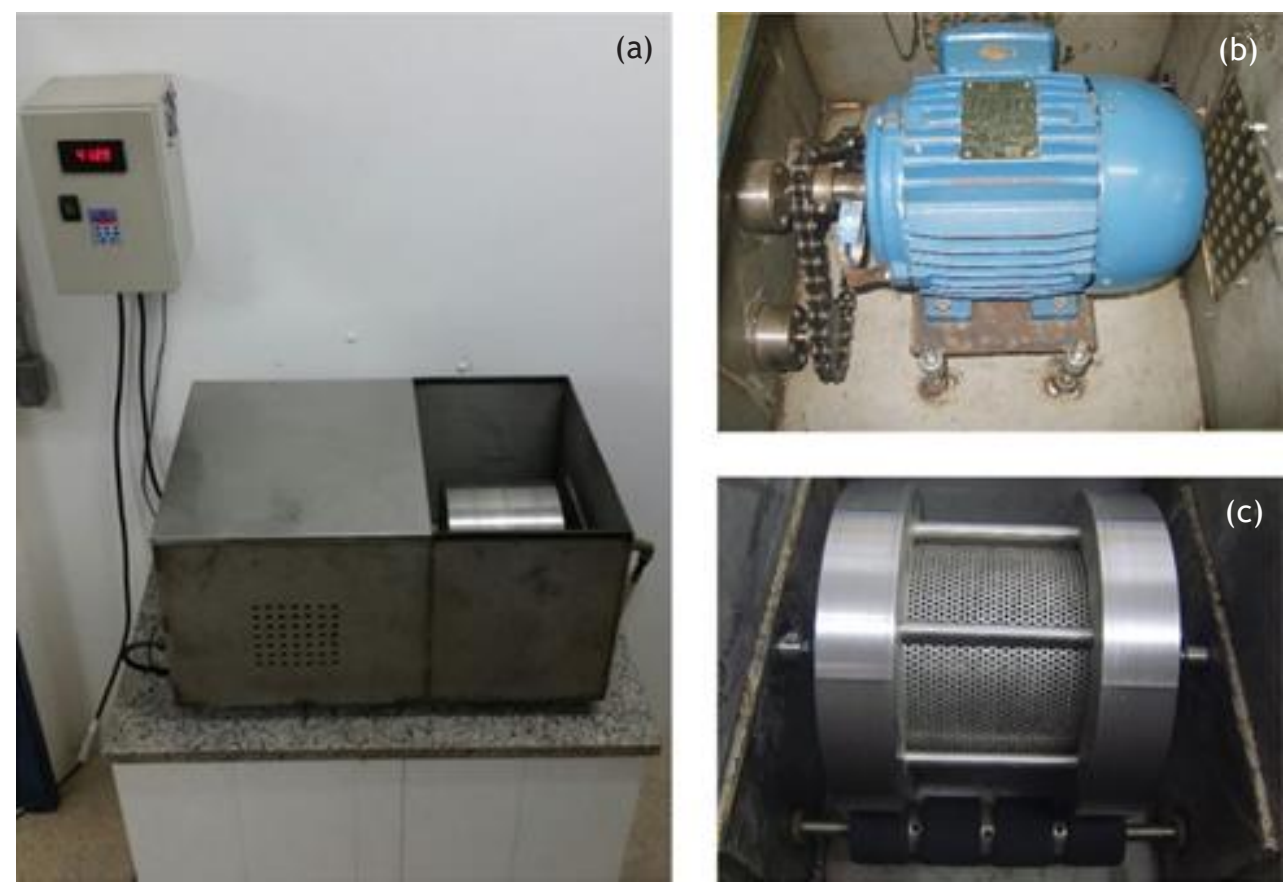

262 Gomes Júnior, P. G. B.; Oliveira, S. R. C. de; Dias Filho, J. L. E. 
Neste trabalho, o índice de perda de massa $\left(I_{P M}\right)$ foi determinado entre a massa inicial e a massa final após o quinto ciclo de desgaste, conforme recomendação de Maia et al. (2002). A Equação 2 expressa a determinação do $I_{P M}(\%)$ no slake durability, na qual $m_{0}$ é a massa inicial (g) da amostra e $m_{5}$ é a massa final (g) da amostra após o quinto ciclo de ensaio.

$I_{P M}=\left(\frac{m_{0}-m_{5}}{m_{0}}\right) \cdot 100$

O Quadro 1 apresenta a classificação da durabilidade de rochas brandas proposta por Maia et al. (2002) adaptada de Gamble (1971).

A escolha pela realização do ensaio ocorreu em virtude de sua medição de capacidade abrasiva, uma vez que se testa o material para aplicabilidade em sistemas urbanos, onde a resistência a esse fator deve ser elevada.

\section{Absorção de água e porosidade}

A NBR 12766 (ABNT, 1992) determina os passos para a obtenção dos parâmetros como absorção de água e porosidade aparentes para rochas aplicadas em revestimento. Os ensaios de absorção de água e medição de porosidade foram realizados em amostras intactas após a realização de cura nas idades de 28 e 90 dias e em amostras submetidas aos ciclos de saturação e secagem nas idades de 35 e 42 dias. Em todos os casos, as amostras foram secadas superficialmente para terem as massas úmidas $m_{u}$ (g) registradas e, em seguida, foram medidas as massas submersas $m_{\text {sub }}(\mathrm{g})$. As amostras foram colocadas na estufa a $105{ }^{\circ} \mathrm{C}$ durante 24 horas e, então, puderam ser obtidas as massas secas $m_{s}(\mathrm{~g})$. O índice de absorção de água (A.A. [\%]) é expresso pela Equação 3 (ABNT, 2005c).

A.A. $=\left(\frac{m_{u}-m_{s}}{m_{s}}\right) \cdot 100$

Eq. 3

A Equação 4, apresentada pela NBR 12766 (ABNT, 1992), determina os valores da porosidade ( $\eta$ [\%])para as amostras estudadas.

$\eta=\left(\frac{m_{u}-m_{s}}{m_{u}-m_{\text {sub }}}\right) .100$

Eq. 4

Para fins de comparação, foram admitidos os valores de referência de absorção de água mínimo de $8 \%$ e máximo de 22\%, estabelecidos pelas NBR 15270-1 (ABNT, 2005a) e NBR 15270-2 (ABNT, 2005b) para blocos cerâmicos, assim como a média dos valores aos 28 dias menor ou igual a $20 \%$ e valores individuais menores ou iguais a 22\%, estabelecidos pela NBR 10836 (ABNT, 2004b) para blocos de solo-cimento sem função estrutural.

\section{Ciclos de saturação e secagem}

Foram realizados ensaios nos quais os CPs foram submetidos a até 70 ciclos de degradação acelerada por saturação e secagem, reproduzindo em laboratório o intemperismo ao qual os materiais de construção são submetidos quando aplicados no ambiente externo.

\section{Quadro 1 - Classificação da durabilidade de materiais rochosos pelo ensaio slake durability}

\begin{tabular}{|l|c|c|c|}
\hline \multirow{2}{*}{$\begin{array}{c}\text { Classificação da } \\
\text { durabilidade }\end{array}$} & \multicolumn{3}{c|}{ Perda de Massa (\%) } \\
\cline { 2 - 4 } & $\mathbf{1}^{\circ}$ ciclo & $\mathbf{2}^{\circ}$ ciclo & $\mathbf{5}^{\circ}$ ciclo \\
\hline Muito alta & $<1$ & $<2$ & $<5$ \\
\hline Alta & $1-2$ & $2-5$ & $5-15$ \\
\hline Medianamente alta & $2-5$ & $5-15$ & $15-40$ \\
\hline Média & $5-15$ & $15-40$ & $40-70$ \\
\hline Baixa & $15-40$ & $40-70$ & $70-80$ \\
\hline Muito baixa & $>40$ & $>70$ & $>80$ \\
\hline
\end{tabular}

Fonte: Maia et al. (2002) 
A Figura 3 apresenta o equipamento automático de saturação e secagem pertencente à UENF que foi empregado na pesquisa. A câmara automática utilizada permite realizar procedimentos de degradação similares aos trabalhos de Dias Filho et al. $(2020,2016)$ para simulação de rochas ornamentais sob efeito dos agentes intempéricos.

No início do processo de degradação acelerada, a bomba é acionada e a água do reservatório é levada para a câmara de degradação durante 15 minutos, para que seja realizada a saturação dos CPs durante 2 horas, com a temperatura variando entre $30{ }^{\circ} \mathrm{C}$ e $40{ }^{\circ} \mathrm{C}$. A seguir, a bomba é acionada novamente e a câmara é esvaziada, devolvendo a água para o reservatório, durante 15 minutos. Assim, os CPs são submetidos a uma secagem a temperatura de $105^{\circ} \mathrm{C}$ durante 2 horas. Entre a secagem e a próxima saturação, há 30 minutos de ventilação para que não ocorra choque térmico, totalizando um ciclo de 5 horas.

As amostras que foram submetidas a este procedimento ficaram sob cura úmida durante 28 dias; logo após, foram inseridas na câmara de degradação e divididas em dois lotes, em que uma metade do número de CPs foi submetida a 35 ciclos de degradação, equivalente a 7 dias, enquanto a outra metade foi submetida a 70 ciclos, equivalente a 14 dias (idade de retirada da câmara de 35 e 42 dias, respectivamente), sob efeitos acelerados de saturação e secagem. Para estes CPs, foram avaliadas propriedades como resistência à compressão uniaxial, absorção de água e porosidade.

Esse procedimento é relevante diante da testagem do material para aplicabilidade em sistemas urbanos, como mobiliários urbanos e pavimentos para ciclovias e calçadas, além de moradias de baixo custo, por exemplo. Isso porque as cidades se tornaram ambientes muito suscetíveis à degradação em curto tempo devido à poluição urbana atrelada, inclusive, a seu crescimento, o que contribui para a diminuição da capacidade mecânica dos materiais e, ainda, o comprometimento da durabilidade e estética dos produtos.

\section{Resultados e discussões}

Os resultados encontrados nos ensaios foram tratados estatisticamente de forma a permitirem extrapolações por meio de verificações em uma quantidade limitada de amostras. Recorreu-se ao critério de Chauvenet para eliminar valores duvidosos, lembrando que esse método se fundamenta na teoria da probabilidade, considerando a eliminação racional de dados fora da tendência dominante (CERQUEIRA, 2017). A seguir, foram determinados indicadores estatísticos de medida de posição central (média) e de medida de dispersão (desvio padrão).

A Tabela 3 apresenta os resultados de resistência à compressão uniaxial média $(\sigma)$ dos CPs que foram curados e ensaiados nas idades de 28 e 90 dias, além daqueles submetidos aos ciclos de saturação e secagem ensaiados nas idades de 35 e 42 dias. Nas células dos resultados, a primeira informação se refere ao valor médio e a segunda informação, ao desvio padrão.

Figura 3 - Equipamento automático de saturação e secagem da UENF: (a) foto geral; e (b) esquema das componentes
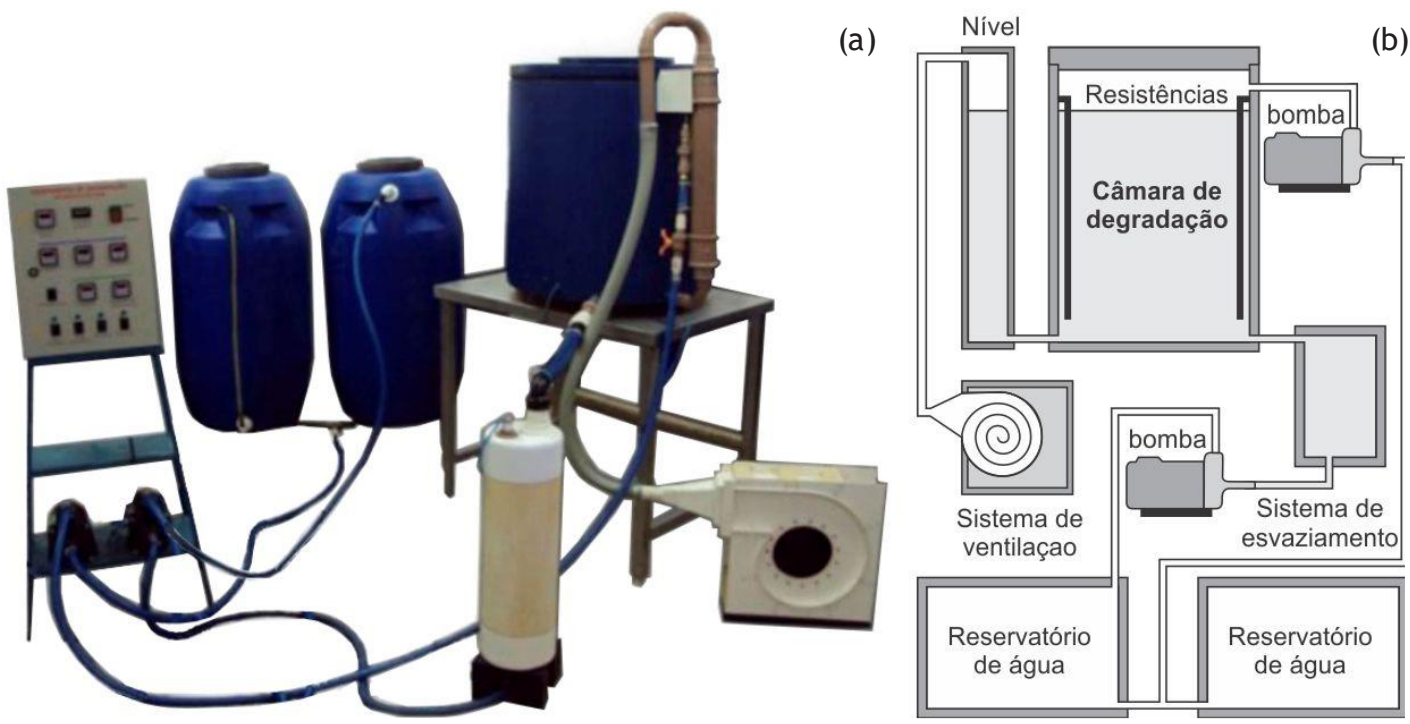

264 Gomes Júnior, P. G. B.; Oliveira, S. R. C. de; Dias Filho, J. L. E. 
Tabela 3 - Resultados de resistência à compressão uniaxial para todos os traços (MPa)

\begin{tabular}{|c|c|c|c|c|c|c|c|c|c|c|c|c|}
\hline \multirow{3}{*}{$\begin{array}{l}\text { Idade } \\
\text { (dias) }\end{array}$} & \multicolumn{12}{|c|}{ Traços } \\
\hline & \multicolumn{4}{|c|}{$1: 3$} & \multicolumn{4}{|c|}{$1: 4$} & \multicolumn{4}{|c|}{$1: 5$} \\
\hline & $0 \%$ & $10 \%$ & $20 \%$ & $30 \%$ & $0 \%$ & $10 \%$ & $20 \%$ & $30 \%$ & $0 \%$ & $10 \%$ & $20 \%$ & $30 \%$ \\
\hline \multirow{2}{*}{28} & 2,56 & 2,68 & 2,94 & 3,10 & 2,79 & 2,22 & 2,40 & 2,08 & 1,46 & 1,38 & 1,62 & 1,69 \\
\hline & 0,14 & 0,02 & 0,08 & 0,04 & 0,17 & 0,03 & 0,01 & 0,02 & 0,10 & 0,02 & 0,06 & 0,06 \\
\hline \multirow{2}{*}{35} & 4,35 & 4,62 & 5,02 & 5,58 & 3,54 & 3,05 & 3,55 & 2,92 & 1,94 & 1,92 & 2,16 & 2,39 \\
\hline & 0,05 & 0,03 & 0,07 & 0,11 & 0,17 & 0,30 & 0,30 & 0,25 & 0,03 & 0,02 & 0,03 & 0,03 \\
\hline \multirow{2}{*}{42} & 3,88 & 4,28 & 3,73 & 4,43 & 3,68 & 3,44 & 3,54 & 2,94 & 2,21 & 1,95 & 2,33 & 1,87 \\
\hline & 0,07 & 0,09 & 0,03 & 0,05 & 0,25 & 0,08 & 0,09 & 0,27 & 0,02 & 0,10 & 0,06 & 0,10 \\
\hline \multirow{2}{*}{90} & 4,36 & 4,53 & 4,96 & 5,08 & 4,29 & 3,66 & 3,82 & 3,44 & 2,40 & 2,62 & 2,65 & 2,65 \\
\hline & 0,11 & 0,01 & 0,27 & 0,28 & 0,24 & 0,11 & 0,04 & 0,04 & 0,03 & 0,08 & 0,02 & 0,10 \\
\hline
\end{tabular}

A Figura 4 apresenta os gráficos de resistência à compressão uniaxial média $(\sigma)$ com variação ao longo do tempo para todos os traços adotados. As linhas horizontais assinalam as tensões correspondentes a 1,5 $\mathrm{MPa}$ e 3,0 MPa, caracterizando os limites mínimos de resistência para blocos cerâmicos com furo horizontal e com furo vertical, respectivamente, sugeridos pela NBR 15270-1 (ABNT, 2005a) e a tensão correspondente a 2,0 MPa para blocos de solo-cimento sem função estrutural, conforme a NBR 10836 (ABNT, 2004b).

Para todos os traços analisados, os resultados de resistência à compressão foram de, no mínimo, 1,5 MPa, ultrapassando em alguns casos o valor de 3,0 MPa estipulado para blocos cerâmicos de vedação com furos verticais (ABNT, 2005a). Considerando o limite mínimo estabelecido pela NBR 10836 (ABNT, 2004b), de 2,0 $\mathrm{MPa}$, apenas as formulações do traço 1:5 apresentaram valores inferiores, ultrapassando esse limite para todos os percentuais de PET, apenas na idade de 90 dias.

A análise mostra que os compósitos ganharam resistência com o aumento do tempo de cura, se comparadas diretamente as amostras não degradadas em câmara nas idades de 28 e 90 dias. Verificou-se também que o aumento do resíduo industrial de lodo de papel diminuiu substancialmente a resistência do compósito.

Por outro lado, ao analisar-se somente a faixa de adição de PET, de $10 \%$ a $30 \%$ em relação ao volume de lodo de papel empregado, notou-se um acréscimo de resistência. Para o traço 1:3, por exemplo, observou-se um aumento de $15,68 \%$ na resistência à compressão aos 28 dias e de 12,14\% aos 90 dias. No traço 1:4 foram obtidas, por exemplo, reduções de $6,31 \%$ aos 28 dias e de $6,01 \%$ aos 90 dias. Para o traço 1:5, o ganho de resistência foi observado nas idades de 28 e 35 dias (22,46\% e $24,45 \%$, respectivamente), com redução da resistência aos 42 dias (4,10\%) e um leve acréscimo de 1,14\% aos 90 dias. Mercante et al. (2018) destacaram que influências como o comprimento das fibras e o tamanho das partículas de PET podem interferir no ganho ou perda de resistência do compósito. Em geral, para baixos teores de incorporação, Galvão et al. (2011) observaram que esses incrementos não proporcionam efeitos substanciais na resistência à compressão do concreto. A literatura afirma que a presença de PET pode colaborar para a perda de resistência, uma vez que ocorre a ruptura das ligações presentes na matriz cimentícia, além de dificultar o empacotamento do compósito (HITA et al., 2018; TAO et al., 2018).

De maneira geral, as amostras que foram degradadas após ciclos de saturação e secagem apresentaram valores intermediários, considerando todo o intervalo entre as idades de 28 a 90 dias, cujos CPs não passaram pelo processo de degradação acelerada. A maior dispersão de resultados ocorreu provavelmente devido ao número reduzido de CPs dentro da câmara de degradação (três por traço).

Para o período de 35 a 42 dias, percebeu-se uma tendência de aproximação entre os valores ou de redução da resistência mecânica. Uma justificativa para isso são as microfissuras geradas nos processos físicos, intensificados aqui pelos ciclos de saturação e secagem (TAO et al., 2018). O aumento dessas microfissuras permite o desenvolvimento de espaços porosos que possibilitam pontos de fraqueza do material, reduzindo sua capacidade mecânica (TAO et al., 2018; MOMENI et al., 2017). Outra justificativa para a redução da resistência mecânica foi descrita por Siddique et al. (2019), que consideraram que a água fria interfere no processo de hidratação do cimento, causando choques térmicos na matriz cimentícia e enfraquecendo-a.

A Tabela 4 apresenta os resultados do índice de perda de massa $\left(I_{P M}\right)$ ao desgaste pelo ensaio slake durability para os CPs que foram curados e ensaiados nas idades de 28 e 90 dias.

A Figura 5 apresenta o gráfico dos índices de perda de massa obtidos pelo slake durability para todos os traços adotados ensaiados nas idades de 28 e 90 dias. 
Figura 4 - Resistência à compressão uniaxial com variação temporal para cada traço (MPa)

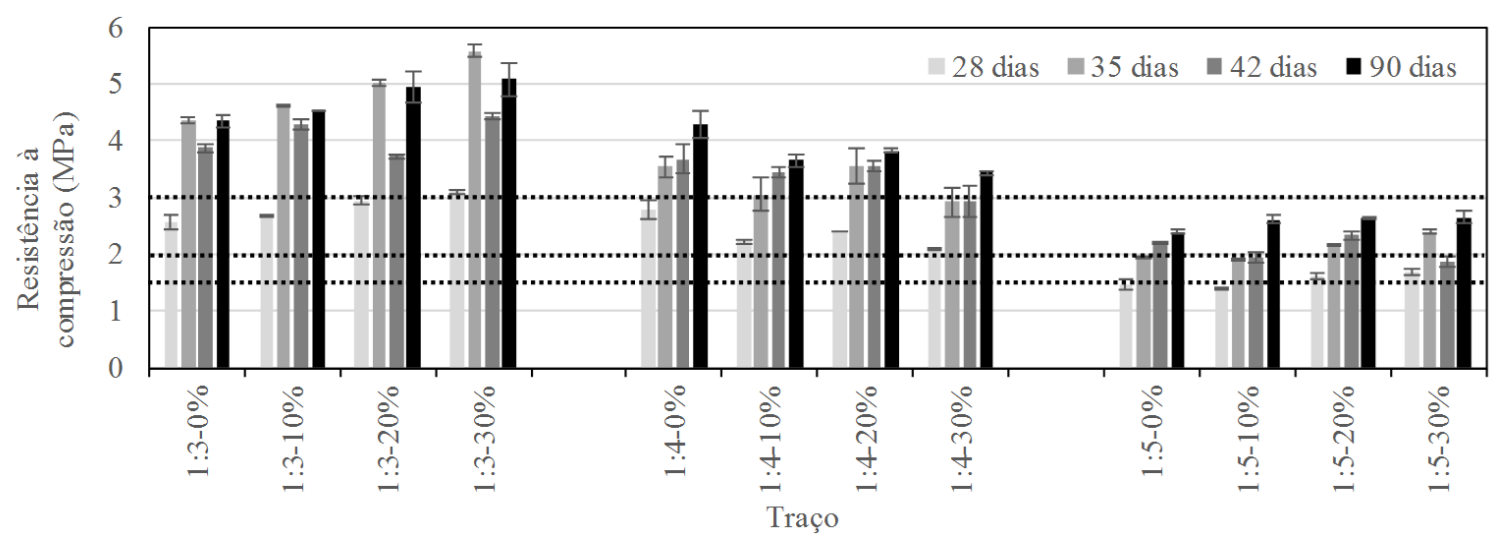

Tabela 4 - Índice de perda de massa para todos os traços (\%)

\begin{tabular}{|c|c|c|c|c|c|c|c|c|c|c|c|c|}
\hline \multirow{3}{*}{$\begin{array}{l}\text { Idade } \\
\text { (dias) }\end{array}$} & \multicolumn{12}{|c|}{ Traços } \\
\hline & \multicolumn{4}{|c|}{$1: 3$} & \multicolumn{4}{|c|}{$1: 4$} & \multicolumn{4}{|c|}{$1: 5$} \\
\hline & $0 \%$ & $10 \%$ & $20 \%$ & $30 \%$ & $0 \%$ & $10 \%$ & $20 \%$ & $30 \%$ & $0 \%$ & $10 \%$ & $20 \%$ & $30 \%$ \\
\hline 28 & 31,34 & 32,79 & 33,13 & 36,38 & 33,84 & 31,83 & 35,46 & 37,06 & 42,56 & 37,72 & 38,96 & 42,84 \\
\hline 90 & 8,44 & 13,86 & 13,48 & 8,86 & 9,04 & 8,23 & 16,21 & 17,34 & 21,16 & 19,17 & 16,16 & 25,70 \\
\hline
\end{tabular}

Figura 5 - Índices de perda de massa pelo slake durability com variação temporal para cada traço (\%)

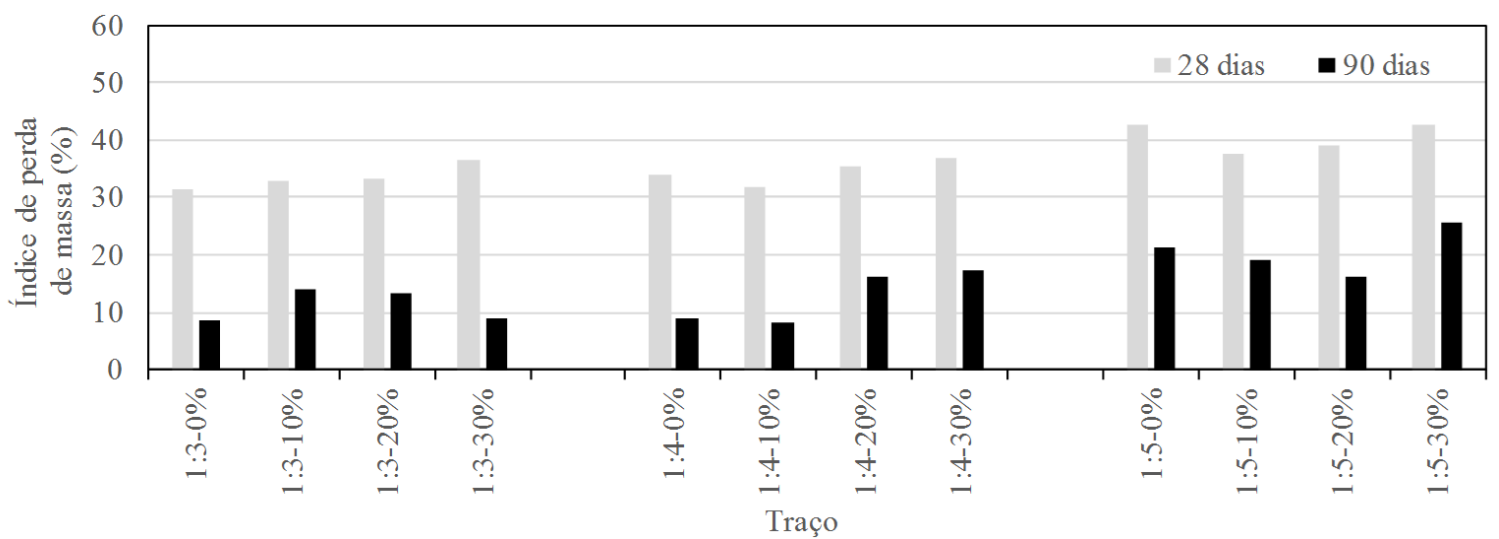

Em geral, percebe-se um aumento da perda de massa do material com a inserção do lodo de papel e do PET, o que pode ser atribuído principalmente à geometria e à disposição irregulares das partículas pontiagudas do polímero, que condicionam uma composição estrutural mais fragmentável ao desgaste. Nota-se, ainda, uma diminuição da perda de massa com o aumento do tempo de cura, o que deve estar relacionado à cicatrização da matriz por efeito da hidratação do cimento (PAIVA, 2007).

De acordo com o que foi apresentado no Quadro 1, conforme Maia et al. (2002), em termos de classificação quanto à durabilidade do compósito após o quinto ciclo de desgaste, verifica-se que se enquadra na categoria de durabilidade medianamente alta após 28 dias de cura, podendo ser caracterizado em uma faixa de durabilidade medianamente alta a alta após 90 dias de cura. As melhores classificações são das formulações de cimento e resíduos de proporção 1:3 e 1:4, enquanto as formulações do traço 1:5 apresentaram valores maiores de perda de massa.

Segundo Vlastelica et al. (2017), o desgaste do material submetido ao ensaio slake durability pode ser avaliado visualmente por três categorias. Quando, após o segundo ciclo de ensaios, o índice de perda de massa for menor que $5 \%$ e as amostras estiverem inalteradas - isto é, ainda houver a quantidade inicial de 10 amostras -, o material é considerado tipo 1; por sua vez, se depois do segundo ciclo, as amostras estiverem fragmentadas entre 15 e 50 pedaços e algumas peças ainda se mostrarem pouco modificadas, o material pode ser considerado tipo 2; por fim, se as amostras estiverem totalmente modificadas, em mais de 200 pedaços, o material é considerado tipo 3. 
De modo geral, para todos os traços analisados, segundo a classificação de Vlastelica et al. (2017), o compósito proposto pode ser considerado do tipo 2, com pouca fragmentação das amostras após o segundo ciclo de desgaste.

A Tabela 5 apresenta os resultados médios de absorção de água (A.A) dos CPs que foram curados e ensaiados nas idades de 28 e 90 dias, assim como das amostras que foram submetidas a ciclos de saturação e secagem e ensaiadas nas idades de 35 e 42 dias. Nas células dos resultados, a primeira informação se refere ao valor médio e a segunda informação, ao desvio padrão.

A Figura 6 apresenta os gráficos com os resultados de absorção de água com variação ao longo do tempo para todos os traços adotados. As linhas horizontais referem-se ao valor mínimo de $8 \%$ conforme a NBR 15270-1 (ABNT, 2005a) e NBR 15270-2 (ABNT, 2005b) de blocos cerâmicos e ao valor médio máximo de 20\% sugerido pela NBR 10836 (ABNT, 2004b) para blocos de solo-cimento sem função estrutural.

A Tabela 6 apresenta os resultados de porosidade $(\eta)$ dos CPs que foram curados e ensaiados nas idades de 28 e 90 dias, assim como os das amostras que foram submetidas aos ciclos de saturação e secagem e ensaiadas nas idades de 35 e 42 dias. Novamente, nas células dos resultados, a primeira informação se refere ao valor médio e a segunda informação, ao desvio padrão.

A Figura 7 apresenta os gráficos de porosidade com variação ao longo do tempo para todos os traços adotados.

Para os ensaios realizados aos 28 dias, todos os traços apresentaram valores médios de absorção de água inferiores a 20\%, conforme recomendação da NBR 10836 (ABNT, 2004b) para blocos de solo-cimento sem função estrutural, mas acima do valor mínimo de 8\% recomendado pela NBR 15270-1 (ABNT, 2005a) e pela NBR 15270-2 (ABNT, 2005b) para blocos cerâmicos. Nas outras idades, os valores de absorção de água para todos os traços foram superiores a $20 \%$.

Tabela 5 - Resultados de absorção de água para todos os traços (\%)

\begin{tabular}{|c|c|c|c|c|c|c|c|c|c|c|c|c|}
\hline \multirow{3}{*}{$\begin{array}{l}\text { Idade } \\
\text { (dias) }\end{array}$} & \multicolumn{12}{|c|}{ Traços } \\
\hline & \multicolumn{4}{|c|}{$1: 3$} & \multicolumn{4}{|c|}{ 1:4 } & \multicolumn{4}{|c|}{$1: 5$} \\
\hline & 0\% & $10 \%$ & $20 \%$ & $30 \%$ & $0 \%$ & $10 \%$ & $20 \%$ & $30 \%$ & 0\% & $10 \%$ & $20 \%$ & $30 \%$ \\
\hline \multirow{2}{*}{28} & 9,32 & 10,49 & 10,57 & 16,32 & 15,49 & 11,68 & 18,01 & 9,98 & 15,93 & 12,02 & 13,76 & 11,23 \\
\hline & 0,40 & 0,90 & 0,53 & 0,25 & 0,94 & 0,76 & 1,86 & 0,25 & 1,44 & 0,56 & 0,43 & 0,43 \\
\hline \multirow{2}{*}{35} & 20,80 & 18,06 & 24,95 & 19,39 & 24,84 & 26,34 & 21,59 & 23,79 & 31,58 & 30,33 & 28,55 & 26,40 \\
\hline & 0,51 & 0,27 & 0,67 & 0,74 & 1,93 & 0,41 & 0,71 & 0,94 & 0,80 & 0,75 & 0,33 & 1,96 \\
\hline \multirow[b]{2}{*}{42} & 45,73 & 42,24 & 42,12 & 38,65 & 37,21 & 41,72 & 37,15 & 43,49 & 45,18 & 46,74 & 45,03 & 46,01 \\
\hline & 0,97 & 0,89 & 0,69 & 0,05 & 0,37 & 0,30 & 0,23 & 0,02 & 0,91 & 0,72 & 0,45 & 0,12 \\
\hline \multirow{2}{*}{90} & 22,10 & 29,65 & 24,25 & 20,57 & 27,29 & 28,26 & 20,22 & 20,61 & 32,81 & 27,21 & 25,99 & 27,50 \\
\hline & 0,50 & 0,21 & 0,10 & 0,24 & 0,04 & 0,26 & 1,07 & 0,31 & 0,26 & 0,30 & 0,62 & 0,36 \\
\hline
\end{tabular}

Figura 6 - Absorção de água com variação temporal para cada traço (\%)

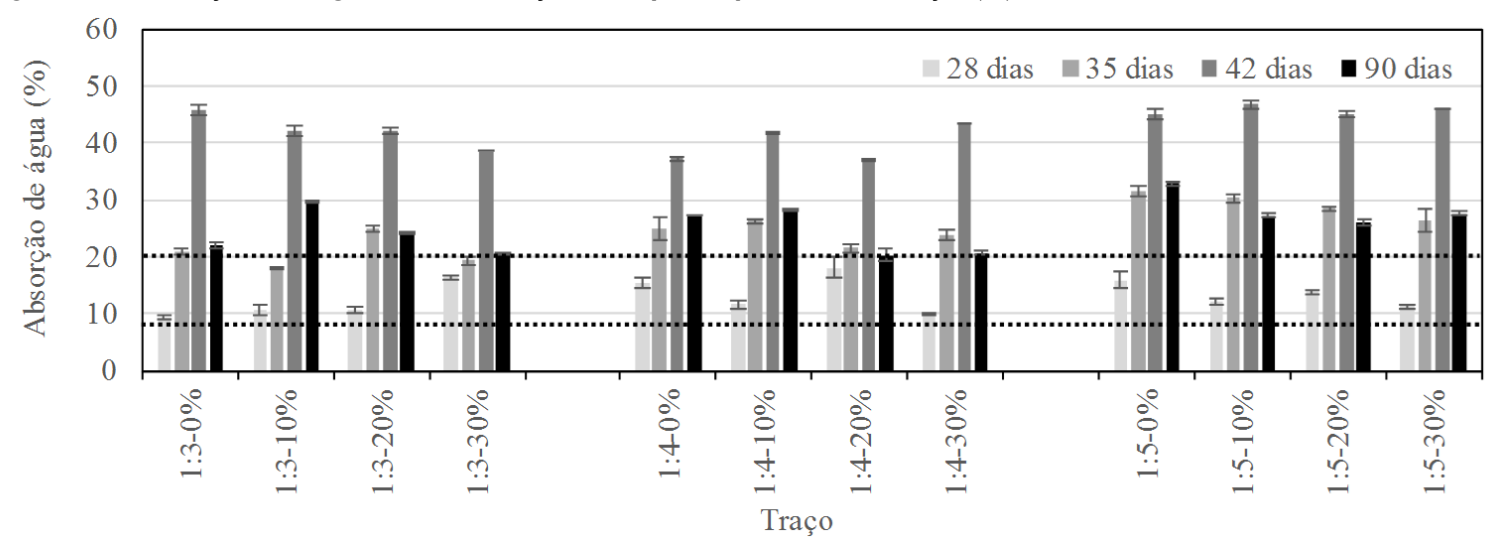


Tabela 6 - Resultados de porosidade para todos os traços (\%)

\begin{tabular}{|c|c|c|c|c|c|c|c|c|c|c|c|c|}
\hline \multirow{3}{*}{$\begin{array}{l}\text { Idade } \\
\text { (dias) }\end{array}$} & \multicolumn{12}{|c|}{ Traços } \\
\hline & \multicolumn{4}{|c|}{$1: 3$} & \multicolumn{4}{|c|}{$1: 4$} & \multicolumn{4}{|c|}{$1: 5$} \\
\hline & $0 \%$ & $10 \%$ & $20 \%$ & $30 \%$ & $0 \%$ & $10 \%$ & $20 \%$ & $30 \%$ & $0 \%$ & $10 \%$ & $20 \%$ & $30 \%$ \\
\hline \multirow{2}{*}{28} & 13,80 & 15,11 & 14,61 & 21,43 & 21,76 & 16,58 & 24,02 & 13,73 & 22,89 & 21,75 & 18,60 & 15,13 \\
\hline & 0,83 & 1,09 & 0,67 & 0,29 & 1,21 & 0,82 & 2,10 & 0,31 & 1,84 & 1,05 & 0,50 & 0,52 \\
\hline \multirow{2}{*}{35} & 29,04 & 24,61 & 29,53 & 22,74 & 29,33 & 31,67 & 28,22 & 27,20 & 36,06 & 33,86 & 34,02 & 29,88 \\
\hline & 0,33 & 1,80 & 1,72 & 0,30 & 0,54 & 1,05 & 1,54 & 2,13 & 3,09 & 2,63 & 1,07 & 1,88 \\
\hline \multirow{2}{*}{42} & 48,64 & 44,26 & 43,85 & 40,85 & 42,93 & 45,17 & 41,89 & 44,86 & 47,30 & 47,42 & 46,99 & 45,92 \\
\hline & 0,32 & 1,91 & 0,83 & 0,24 & 0,17 & 0,13 & 0,82 & 0,82 & 1,30 & 0,55 & 0,59 & 0,32 \\
\hline \multirow{2}{*}{90} & 28,48 & 35,81 & 29,79 & 25,78 & 35,17 & 34,94 & 26,17 & 25,64 & 39,57 & 33,49 & 31,43 & 32,57 \\
\hline & 0,17 & 0,23 & 0,36 & 0,28 & 0,05 & 0,17 & 1,15 & 0,56 & 0,05 & 0,70 & 0,58 & 0,20 \\
\hline
\end{tabular}

Figura 7 - Porosidade com variação temporal para cada traço (\%)

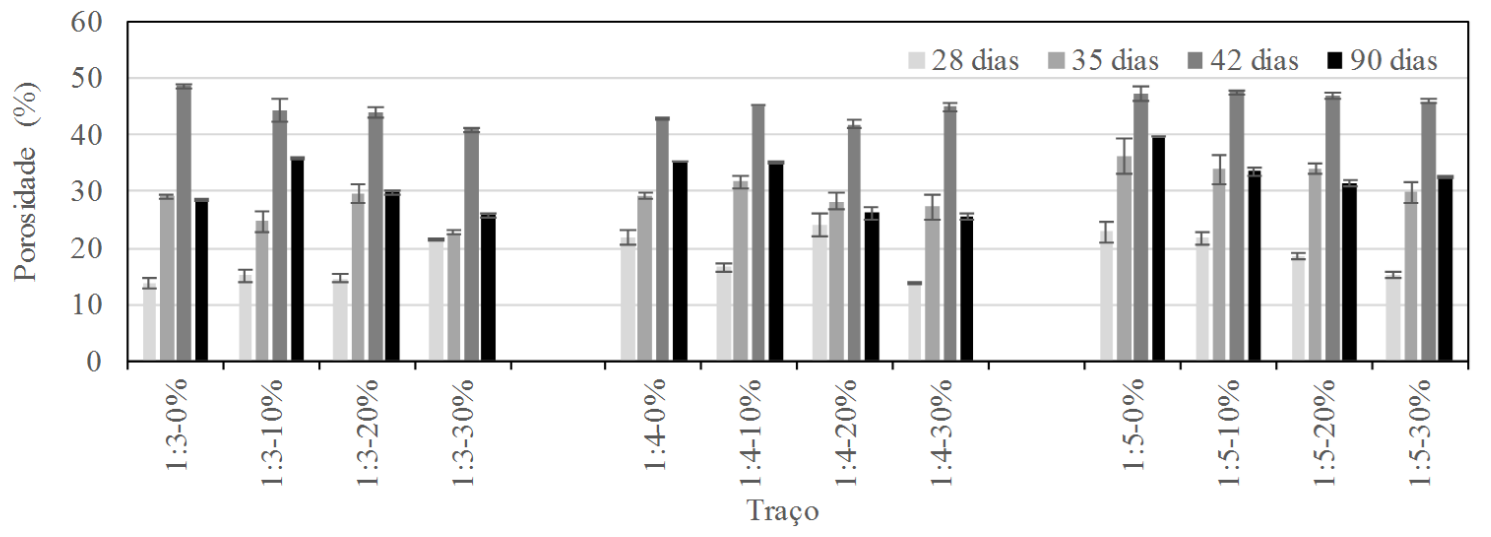

De modo geral, observa-se uma elevação dos valores de absorção de água e de porosidade conforme aumenta a quantidade de resíduos na mistura, inversamente proporcional ao que acontece com a resistência mecânica, conforme esperado. Os valores também aumentam com o passar do tempo em uma comparação direta entre as amostras não degradadas em câmara ensaiadas aos 28 dias e aos 90 dias. Uma justificativa para que esse aumento tenha ocorrido é a condição heterogênea do composto, especialmente quando se acrescenta flakes de PET. Na condição degradada, as amostradas alcançam valores bem altos já aos 35 dias (compatíveis com os valores para 90 dias das amostras sem degradação em câmara), atingindo condição mais crítica nos ensaios aos 42 dias. $\mathrm{O}$ aumento do valor de absorção de água, principalmente com o acréscimo de resíduo de papel, muito se deve à capacidade intrínseca de absorção por conta da celulose. E a capacidade de aglomeração do resíduo celulósico e sua dificuldade de se incorporar ao cimento e os flakes de PET favorecem o surgimento de poros (PAIVA, 2007).

Como abordado nos resultados de resistência mecânica para o período de 35 a 42 dias, no qual ocorreu um aumento significativo da absorção de água, uma explicação pode ser dada a partir das microfissuras que são geradas na matriz cimentícia e que se intensificam nos ciclos de molhagem e secagem, permitindo o desenvolvimento de espaços porosos e aumentando a absorção de água (DIAS FILHO et al., 2020, 2016; GALVÃO et al., 2011). Com relação ao aumento de teor de PET, não foi possível encontrar uma estabilidade de comportamento quanto à absorção de água do compósito. Segundo Mercante et al. (2018), o incremento de flakes de PET proporciona um aumento da absorção de água, especialmente relacionado à presença e ao tamanho das partículas de PET.

\section{Conclusão}

Este artigo apresentou um compósito constituído de cimento, resíduos de efluente de uma indústria de papel e flakes de PET, em proporções de 1:3, 1:4 e 1:5 de cimento e resíduos, com substituições em teores de 10\%, $20 \%$ e $30 \%$ do volume de lodo de papel por PET. Foram investigadas as propriedades físico-mecânicas e de desgaste do compósito - como a resistência à compressão uniaxial, a absorção de água e a porosidade - além da perda de massa pelo desgaste ao atrito no ensaio slake durability aos 28 e aos 90 dias. As avaliações 
físico-mecânicas também foram realizadas em amostras que passaram por processo de degradação acelerada e consistiram em ciclos de saturação e secagem durante 7 e 14 dias, ao completarem 35 e 42 dias de idade, respectivamente.

Quanto à resistência à compressão, o aumento da proporção de lodo de papel no compósito é inversamente proporcional ao ganho de resistência; no que se refere à adição de flakes de PET no compósito, há uma tendência para o ganho de resistência, conforme observado nos traços 1:3 e 1:5, embora para o traço 1:4 seja observada uma redução na resistência. Também, o aumento do tempo de cura promoveu aumento no valor da resistência mecânica. De maneira geral, os resultados obtidos atenderam aos limites normativos de materiais comparativos como solo-cimento e alvenaria cerâmica. Mesmo o traço com maior quantidade de resíduos (1:5) apresentou resultados satisfatórios para idades superiores a 28 dias.

Sobre o slake durability, que representa o indicativo de durabilidade relacionada ao desgaste do material, comparando os resultados dos ensaios aos índices de degradação indicados em normas específicas, percebeu-se uma tendência de resistência ao desgaste por atrito similar aos materiais classificados como de medianamente alta a alta durabilidade, mesmo não sendo de natureza rochosa, com essa medida de desempenho inversamente proporcional à quantidade de resíduo no compósito.

Quanto à absorção de água e à porosidade, percebeu-se um aumento desses valores com o acréscimo da quantidade de resíduos e aumento do tempo de cura. Notou-se, ainda, uma relação inversa com a resistência mecânica, conforme esperado. Os valores foram ainda mais críticos para as amostras submetidas aos ciclos de degradação acelerada. Embora, na maioria dos resultados, a absorção de água tenha atingido um patamar elevado quando comparada aos limites normativos de outros materiais, sugere-se a resolução desse problema utilizando um traço que consuma menos resíduo de lodo de papel pelo fato de ser um componente higroscópico ou, ainda, adotando soluções que minimizem o umedecimento do compósito, como impermeabilizantes e vernizes ecológicos, entre outros.

De modo geral, o compósito apresenta condições de se tornar uma alternativa para atender as necessidades dos sistemas urbanos das cidades, como em equipamentos da administração pública, mobiliários urbanos, blocos intertravados para calçamento e pavimentação de leve tráfego, tijolos e blocos estruturais para habitações de menor valor econômico, entre outros. Ainda são necessárias avaliações mais aprofundadas, além das físico-mecânicas e de degradação aqui testadas, que corroborem e validem o compósito como um produto condizente com práticas mais sustentáveis que minimizam os impactos ambientais e que aumentam a vida útil dos produtos.

\section{Referências}

ABDEL-SHAFY, H. I.; MANSOUR, M. S. M. Solid waste issue: sources, composition, disposal, recycling, and valorization. Egyptian Journal of Petroleum, v. 27, n. 4, p. 1275-1290, dez. 2018.

AHMAD, M. et al. Correlation between strength and durability indices of rocks-soft computing approach. Procedia Engineering, v. 191, p. 458-466, 2017.

AMARAL JÚNIOR, J. C. et al. Análise experimental da adição de fibras poliméricas nas propriedades mecânicas do concreto. Matéria, Rio de Janeiro, v. 22, n. 1, 2017.

AMERICAN SOCIETY FOR TESTING AND MATERIALS. D4644: standard test method for slake durability of shales and similar weak rocks. West Conshohocken, 2008.

ASSOCIAÇÃO BRASILEIRA DE NORMAS TÉCNICAS. NBR 10004: resíduos sólidos: classificação. Rio de Janeiro, 2004a.

ASSOCIAÇÃO BRASILEIRA DE NORMAS TÉCNICAS. NBR 10836: bloco de solo-cimento sem função estrutural: análise dimensional, determinação da resistência à compressão e da absorção de água. Rio de Janeiro, 2004b.

ASSOCIAÇÃO BRASILEIRA DE NORMAS TÉCNICAS. NBR 12766: rochas para revestimento: determinação da massa específica aparente, porosidade aparente e absorção de água aparente. Rio de Janeiro, 1992.

ASSOCIAÇÃO BRASILEIRA DE NORMAS TÉCNICAS. NBR 15270-1: componentes cerâmicos: parte 1: blocos cerâmicos para alvenaria de vedação: terminologia e requisitos. Rio de Janeiro, 2005a.

ASSOCIAÇÃO BRASILEIRA DE NORMAS TÉCNICAS. NBR 15270-2: componentes cerâmicos: parte 2: blocos cerâmicos para alvenaria de vedação: terminologia e requisitos. Rio de Janeiro, $2005 \mathrm{~b}$. 
ASSOCIAÇÃO BRASILEIRA DE NORMAS TÉCNICAS. NBR 15270-3: componentes cerâmicos: parte 3: blocos cerâmicos para alvenaria estrutural e de vedação: métodos de ensaio. Rio de Janeiro, 2005c.

ASSOCIAÇÃO BRASILEIRA DE NORMAS TÉCNICAS. NBR 7215: cimento Portland: determinação da resistência à compressão. Rio de Janeiro, 1996.

AZEVEDO, A. R. G. et al. Recycling paper industry effluent sludge for use in mortars: a sustainability perspective. Journal of Cleaner Production, v. 192, p. 335-346, ago. 2018.

BRASIL. Lei $\mathbf{n}^{\mathbf{0}}$ 12.305, de 2 de agosto de 2010, que institui a Política Nacional de Resíduos Sólidos; altera a Lei no 9.605, de 12 de fevereiro de 1998; e dá outras providências. Disponível em:

http://www.planalto.gov.br/ccivil_03/_Ato2007-2010/2010/Lei/L12305.htm. Acesso em: 15 mar. 2019.

CASTRO, M. A. M. et al. Avaliação das propriedades físicas e mecânicas de blocos de solo-cimento formulados com coprodutos siderúrgicos. Matéria, Rio de Janeiro, v. 21, n. 3, p. 666-676, set. 2016.

CERQUEIRA, N. A. Parâmetros físicos e mecânicos de blocos prensados e queimados de cerâmica vermelha para uso como alvenaria estrutural. Campos dos Goytacazes, 2017. Tese (Doutorado em Engenharia Civil) - Universidade Estadual do Norte Fluminense Darcy Ribeiro, Campos dos Goytacazes, 2017.

CERYAN, S. New weathering indices for evaluating durability and weathering characterization of crystalline rock material: a case study from NE Turkey. Journal of African Earth Sciences, v. 103, p. 54 64, mar. 2015.

CORDEIRO, M. E. V. M. et al. educação ambiental e o uso do solo cimento. Vértices, v. 8, n. 1/3, p. 35-54, 2006.

DIAS FILHO, J. L. E. et al. Durability of ornamental gneiss stones from Pádua, Rio de Janeiro, Brazil. Journal of Materials in Civil Engineering, v. 32, n. 7, abr. 2020.

DIAS FILHO, J. L. E. et al. Durability of ornamental gneisses from Pádua-RJ as covering stone. The Eletronic Journal of Geotechnical Engineering, v. 21, p. 1957-1976, 2016.

FOSTER, A. et al. Economia circular e resíduos sólidos: uma revisão sistemática sobre a eficiência ambiental e econômica. In: ENCONTRO INTERNACIONAL SOBRE GESTÃO EMPRESARIAL E MEIO AMBIENTE, São Paulo, 2016. Anais [...] São Paulo, 2016.

GALVÃO, J. C. A. et al. Use of waste polymers in concrete for repair of dam hydraulic surfaces. Construction and Building Materials, v. 25, n. 2, p.1049-1055, fev. 2011.

GAMBLE, J. C. Durability-plasticity classification of shales and other argillaceous rocks. Ph.D. Thesis, University of Illinois, 1971.

HITA, P. R. et al. Reuse of plastic waste of mixed polypropylene as aggregate in mortars for the manufacture of pieces for restoring jack arch floors with timber beams. Journal of Cleaner Production, v. 198, p. 1515-1525, out. 2018.

MAIA, P. C. A. et al. Alterabilidade de Rochas Basálticas: caracterização petrográfica. Solos e Rochas, v. 25, n. 3, p. 207-220, 2002.

MARCHI, C. M. D. F. Novas perspectivas na gestão do saneamento: apresentação de um modelo de destinação final de resíduos sólidos urbanos. Urbe - Revista Brasileira de Gestão Urbana, v. 7, n. 1, p. 91 105, abr. 2015.

MERCANTE, I. et al. Mortar and concrete composites with recycled plastic: a review. Science and Technology of Materials, v. 30, p. 69-79, Dez. 2018.

MOMENI, A. et al. The effect of weathering on durability and deformability properties of granitoid rocks. Bulletin of Engineering Geology and the Environment, v. 76, n. 3, p. 1037-1049, jan. 2017.

NEVILLE, A. M.; BROOKS, J. J. Tecnologia do concreto, 2. ed., Porto Alegre: Bookman, 2013.

NOVÁKOVÁ, K. et al. Experimental development of a plastic bottle usable as a construction building block created out of polyethylene terephthalate: testing PET(b)rick 1.0. Journal of Building Engineering, v. 12, p. 239-247, jul. 2017.

270 Gomes Júnior, P. G. B.; Oliveira, S. R. C. de; Dias Filho, J. L. E. 
OLIVEIRA, A. S. Análise ambiental da viabilidade de seleção de produtos da construção civil através da ACV e do software BEEs 3.0. Porto Alegre, 2007. Dissertação (Mestrado em Engenharia Civil) Escola de Engenharia, Universidade Federal do Rio Grande do Sul, Porto Alegre, 2007.

OLIVETTI, E. A.; CULLEN, J. M. Toward a sustainable materials system. Science, v. 360, n. 6396, p. 1396-1399, jun. 2018.

ORGANIZAÇÃO DAS NAÇÕES UNIDAS. Programa de Desenvolvimento das Nações Unidas. Transformando nosso mundo: a Agenda 2030 para o desenvolvimento sustentável. Disponível em: http://www.br.undp.org/content/dam/brazil/docs/agenda2030/undp-br-Agenda2030-completo-pt-br2016.pdf. Acesso em: fev. 2019.

PAIVA, S. N. Compósito cimento-lodo de ETE de indústria de papel para aplicação na construção civil. Piracicaba, 2007. Dissertação (Mestrado em Engenharia Civil) - Universidade de São Paulo, Piracicaba, 2007.

PINHEIRO, R. M. Reciclagem de lodo primário da estação de tratamento de efluentes da indústria de papel em cerâmica argilosa. Campos dos Goytacazes, 2008. Dissertação (Mestrado em Engenharia Civil) Universidade Estadual do Norte Fluminense Darcy Ribeiro, Campos dos Goytacazes, 2008.

ROCHA, E. R. da. Optimização de métodos de escolha de materiais com base no desempenho sustentável. Florianópolis: UFSC, 2017. Disponível em: https://riuni.unisul.br/handle/12345/4652. Acesso em: 04 nov. 2020.

ROCHA, T. S. V. Resíduos de construção e demolição como substituto parcial do cimento: efeito na durabilidade em materiais cimentícios. Porto, 2016. Dissertação (Mestrado em Engenharia Civil) Universidade do Porto, Porto, 2016.

RODRIGUES, C. R. P.; MENTI, M. M. Resíduos sólidos: gerenciamento e políticas públicas federais. Cadernos do Programa de Pós-Graduação: DIREITO/UFRGS, v. 11, n. 3, p. 59-79, dez. 2016.

SANTORO, J. F.; KRIPKA, M. Determinação das emissões de dióxido de carbono das matérias primas do concreto produzido na região norte do Rio Grande do Sul. Ambiente Construído, Porto Alegre, v.16, n. 2, p. 35-49, abr./jun. 2016.

SANTOS, C. M. A. et al. Processo de reciclagem química de PET em meio alcalino: efeito da concentração do íon hidróxido, da cor do PET e do tempo de reação. Matéria, Rio de Janeiro, v. 23, n. 4, 2018.

SIDDIQUE, S. et al. Sustainable utilisation of ceramic waste in concrete: exposure to adverse conditions. Journal of Cleaner Production, v. 210, p. 246-255, fev. 2019.

SINDICATO NACIONAL DA INDÚSTRIA DO CIMENTO. Dados do setor. SNIC, 2016. Disponível em: http://snic.org.br/numeros-do-setor.php. Acesso em: fev. 2019.

SIQUEIRA, F. B. et al. Influence of industrial solid waste addition on properties of soil-cement bricks. Cerâmica, v. 62, n. 363, p. 237-241, set. 2016.

SOLER, F. D. Desafios jurídicos para implementação da logística reversa no Brasil. Feslberg, 2015. Disponível em: http://www.felsberg.com.br/desafios-juridicos-para-implementacao-da-logistica-reversa-nobrasil/. Acesso em: abr. 2019.

TAO, G. et al. Utilization of sandy soil as the primary raw material in production of unfired bricks. Advances in Materials Science and Engineering, v. 2018, p. 1-11, fev. 2018.

VASCONCELOS, Y. Planeta plástico: criado há cerca de um século, o material polimérico que trouxe inúmeras facilidades à vida moderna tornou-se fonte de um enorme problema ambiental. Revista Fapesp, São Paulo, v. 281, p. 19-24, jul. 2019.

VIEIRA, C. M. F. et al. Clay bricks added with effluent sludge from paper industry: technical, economical and environmental benefits. Applied Clay Science, v. 132-133, p. 753-759, nov. 2016.

VLASTELICA, G. et al. Testing the shear strength of soft rock at different stages of laboratory simulated weathering. Journal of the Croatian Association of Civil Engineers, v. 68, n. 12, p. 955-965, jan. 2017.

\section{Agradecimentos}

O presente trabalho foi realizado com apoio da Coordenação de Aperfeiçoamento de Pessoal de Nível Superior - Brasil (CAPES) - Código de Financiamento 001. Os autores agradecem ao Instituto Federal de 
Educação, Ciência e Tecnologia Fluminense (IFFluminense) pela viabilidade desta pesquisa e à Universidade Estadual do Norte Fluminense Darcy Ribeiro (UENF) pelas instalações físicas e suporte dados.

Programa de Pós-graduação em Arquitetura e Urbanismo | Instituto Federal de Educação, Ciência e Tecnologia Fluminense | E-mail: sergio.oliveira@iff.edu.br

\section{José Luiz Ernandes Dias Filho}

Laboratório de Egenharia Civil | Universidade Estadual do Norte Fluminense Darcy Ribeiro | Av. Alberto Lamego, 2000, Laboratório:

01/P7, Parque California | Campos dos Goytacazes - RJ - Brasil | CEP 28013-602 | Tel.: (22) 2739-7324 | E-mail: jlernandes@hotmail.com

\section{Ambiente Construído}

Revista da Associação Nacional de Tecnologia do Ambiente Construído Av. Osvaldo Aranha, $99-3^{\circ}$ andar, Centro

Porto Alegre - RS - Brasil

$$
\text { CEP } 90035-190
$$

Telefone: +55 (51) 3308-4084

www.seer.ufrgs.br/ambienteconstruido

$$
\text { www.scielo.br/ac }
$$

E-mail: ambienteconstruido@ufrgs.br 